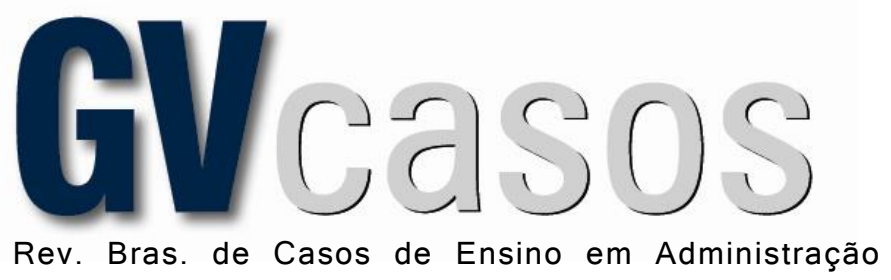

DOI: http://dx.doi.org/10.12660/gvcasosv11n2c15

\title{
DILEMAS ENTRE O REAL E O VIRTUAL NA INTERNACIONALIZAÇÃO: O CASO RILIX
}

Real versus virtual dilemma in internatization: the Rilix case

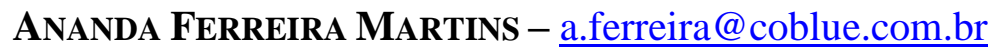

Universidade do Vale do Itajaí - Balneáreo Camboriu, SC, Brasil

SílVIo Luís DE VASCONCELLOS - silvio.vasconcellos@espm.br

Escola Superior de Propaganda e Marketing - São Paulo, SP, Brasil

Cyntia Vilasboas Calixto - cyntia.calixto@ fgv.br

Escola de Administração de Empresas de São Paulo da FGV - São Paulo, SP, Brasil

Submissão: 20/07/2020 | Aprovação: 02/07/2021

\begin{abstract}
Resumo
O caso estabelece um paralelo entre os dilemas de Selena e a experiência de internacionalização da Rilix, startup que desenvolve softwares e equipamentos de realidade virtual. Contratada recentemente Selena lida com os desafios da expansão da empresa e com seus próprios desafios profissionais.
\end{abstract}

Palavras-chave: Internacionalização, cultura organizacional, liderança, inovação em modelos de negócios, carreira.

\begin{abstract}
The case draws a parallel between Selena's dilemmas and the internationalization experience of Rilix, a startup that develops software and virtual reality equipment. Recently hired, Selena deals with the company's expansion challenges and with her own professional ones.

Keywords: Internationalization, organizational culture, leadership, business model innovation, career.
\end{abstract}

\section{Selena e a Rilix}

Este não é um caso trivial de internacionalização. Ele estabelece um paralelo entre os dilemas de Selena e a experiência de internacionalização da Rilix, startup que desenvolve softwares e equipamentos de realidade virtual. Dada a oportunidade de expandir operações para o exterior, surgem desafios para a empresa e para Selena, contratada recentemente, com a missão de liderar esse processo. Enquanto a empresa deve descobrir, simultaneamente, a medida certa entre inovar no modelo de negócios, competir internacionalmente e adaptar a cultura organizacional, Selena tem o dilema de coordenar a expansão da empresa, conectando seus objetivos pessoais e os da empresa.

Primeiramente, vamos fazer um flashback para relatar como Selena conheceu a startup e como se engajou no projeto de internacionalização. Ela recém havia retornado do Havaí. Havia passado seis meses em uma terra distante aprendendo o idioma e a cultura, tentando absorver ao máximo a energia do lugar. Antes disso, ela não estava em paz consigo mesma, não estava contente com seu estágio e, ao finalizar o curso de Relações Internacionais, não se sentiu pronta para iniciar sua carreira. Aquela viagem caiu como uma luva para mudar o rumo. De volta, buscava organizar sua decolagem profissional e conciliar seus sonhos, aos 23 anos. Matriculou-se em uma 
especialização em Marketing Internacional e estava de volta à universidade, às calçadas de sua cidade e à ciclovia.

Era estranho voltar. Não se sentia mais em casa, mas também não sentia que permanecer longe pudesse ser a solução. Para Selena, quando se viaja e permanece tempo suficiente para absorver parte da cultura do outro país, uma espécie de mescla cultural se estabelece com o passado. É como se os lugares se misturassem. Quando se volta, pensava ela, não se volta para o que era antes, enquanto refletia as palavras de Robert Louis Stevenson, no livro O Emigrante Amador, de 1895, e ainda tão atual: "Não há terra estrangeira; o estrangeiro é o viajante"1. Caro Robert, pensava, também quando se volta, não se deixa de ser um pouco estrangeiro, mesmo em sua terra natal.

Selena tinha voltado e, como muitos leitores deste caso, queria encontrar seu espaço profissional para realizar seus sonhos. Queria finalizar sua especialização e sair de uma zona de conforto que algumas pessoas recém-graduadas tendem a manter em seu ninho familiar. Havia tomado um caminho alternativo que lhe trouxe a experiência de viver no estrangeiro, mas, agora, queria assumir um desafio profissional, que lhe desse independência e realização. Precisava reorganizar-se, estruturar um novo começo. No entanto, a vivência fora do país abriu-lhe alguns horizontes e ajudou-a a definir mais o que não queria fazer do que, propriamente, um rumo a seguir.

Não queria sacrificar sua vida, seu tempo e sua energia trabalhando em algo que não lhe trouxesse motivação. Idealizava o emprego dos sonhos em meio a um Brasil em crise, ouvindo sua mãe reclamar das contas, vendo as portas da empresa familiar de 25 anos se fecharem, observando cortes de custos e de pessoas sendo realizados em várias empresas poderosas, escutando como o Brasil estava em dificuldades. Chegou a pensar que talvez houvesse cometido um erro, que não deveria ter voltado, que deveria ter sido mais corajosa ou talvez ido para outro lugar depois do Havaí, em vez de voltar ao Brasil. As dúvidas de qual caminho seguir a rondavam, impiedosamente.

Em um fim de semana de abril de 2018, entretanto, parecia ter chegado a hora. Estava assistindo a uma palestra na universidade. Três palestrantes falariam sobre vivência e cultura nas empresas. Dois eram empresários renomados, com formação acadêmica, munidos de conceitos que fundamentavam seus anos de experiência, concentrados em mostrar aos alunos de pós-graduação as maneiras de reduzir os riscos no universo corporativo, falando sobre comando e controle, hierarquia, reuniões e poder. Enquanto discursavam, Selena estava mais interessada em suas redes sociais do que em absorver a vivência daquelas duas pessoas cultas e vividas. No fundo, sentia que havia mais do mesmo no tom de voz e no conteúdo, e se permitiu dispersar.

$\mathrm{O}$ terceiro palestrante, no entanto, pareceu-lhe uma figura intrigante. Era jovem e, ao mesmo tempo, parecia intelectual, despojado e divertido, dono de uma voz imponente e, ao mesmo tempo, despretensiosa, que o distinguia da imagem que a formação acadêmica de Selena na área de Relações Internacionais e de Gestão havia construído em sua mente. Quando o jovem empresário começou a falar, Selena esqueceu as conversas nos aplicativos, deixou de lado o notebook e prestou atenção naquela história que desconstruía seu estereótipo de empresário, estruturada em teorias que lhe pareciam abstrações, enquanto o palestrante arrancava risos dos estudantes.

Ele falava de uma startup de apenas quatro anos, que havia surgido de uma ideia dele e de seu primo de criar um simulador de realidade virtual, que replicava uma montanha-russa, fazia as pessoas mergulharem em um universo virtual e se esquecerem de onde estavam. Contou que buscaram um carrinho em uma sucata do Beto Carrero - parque temático da região sul do Brasil - e o levaram para uma feira especializada em entretenimento para parques e festas, em São Paulo. Naquela feira, venderam um protótipo e a promessa de desenvolver vários cenários para o brinquedo curioso e inovador. O resultado foi a venda de 13 simuladores, a entrada de uma receita de $\mathrm{R} \$ 500$

\footnotetext{
${ }^{1}$ Stevenson, R. L. (1895). The amateur emigrant: Across the plains. The Silverado Squatters (Vol. 15). New York: Scribner.
} 
mil e muito trabalho nos meses seguintes para cumprir o prometido. Em sua fala eloquente, ele desconstruía alguns conceitos levantados pelos palestrantes anteriores. Quando questionado sobre riscos, ele dizia: "Nós queremos"; quando perguntado sobre erros, dizia: "Se você errar e aprender, então o erro já terá valido a pena". O nome do palestrante não poderia ser mais apropriado: Lennon, imagine!

Selena não conseguia acreditar que uma empresa assim existisse, muito menos com um CEO como aquele! Enquanto parecia ser um visionário, falava também em corte de custos, em enxugamento da equipe e como muitas pessoas não se adaptavam ao perfil da empresa. Mesmo assim, Selena resolveu tentar fazer parte daquilo. Anotou o e-mail do palestrante e enviou, imediatamente, uma mensagem no mesmo tom de sua palestra. Contou que havia ficado bastante curiosa e que, caso ele tivesse realizado um corte de pessoal e estivesse precisando de alguém com muita vontade trabalhar, ela estava disposta a colaborar. Não esperava muito da mensagem, mas o palestrante respondeu educadamente que ficaria feliz de recebê-la e mostrar-lhe a empresa.

Selena preparou-se para a entrevista. Levou currículos impressos e colocou uma camisa de botão que nem de longe representava sua personalidade. Era a forma como ela havia aprendido que deveria estar em uma possível entrevista de emprego. Esperava por aquilo há meses e não queria errar. Chegando ao endereço, Selena foi recebida por uma equipe de pessoas jovens, simples, de tênis e camiseta.

A conversa foi com o palestrante, seu primo e a responsável pelo Marketing da empresa. Durante a entrevista, Selena não sabia bem com quem estava falando. Foi uma conversa informal que durou duas horas de risadas e troca de experiências. Ela estava extasiada! Não conseguia ser nada além de transparente. Contou sobre sua caminhada até ali, da viagem ao Havaí, sobre o que ela acreditava, sobre a forma como gostava de trabalhar e por que havia deixado o ramo da Logística, havia pouco mais de seis meses, antes da viagem. Ao fim da entrevista, Selena sentia-se leve. Era ali o seu lugar. Notou que havia um sentimento recíproco entre ela e a equipe da Rilix. Voltando para casa, abriu o notebook e foi pesquisar. Era hora de conhecer um pouco mais sobre este mundo em que estava prestes a embarcar. Precisava conhecer mais sobre o universo da realidade virtual.

\section{$O$ universo da realidade virtual}

A tecnologia de realidade virtual faz uso de dispositivos para que os usuários imerjam em um ambiente simulado. Faz uso de fones de ouvido e visor especialmente projetados e, em alguns casos, inclui dispositivos sensoriais que envolvem o olfato e o tato. Dispositivos ópticos como Oculus Rift, do Facebook, e PlayStation Virtual Reality, da Sony, vendem milhões de unidades, à medida que os consumidores procuram explorar as possibilidades oferecidas pelos ambientes virtuais ${ }^{2}$. Segundo divulgado pela Revista Época (Época, 2016), a consultoria CCS Insight estima que o número de unidades vendidas de visores de realidade virtual tenha passado de 2,5 milhões em 2015. O site especializado em comportamento do consumidor Statista, já incorporando as oscilações decorrentes da pandemia Covid-19, estima que, até 2023, o mercado de realidade virtual ultrapasse os US\$ 5 bilhões. Os dados de vendas e projeções estão ilustrados na Figura 1.

\footnotetext{
${ }^{2}$ Statista (2020). Consumer virtual reality software and hardware market size worldwide from 2016 to 2023. Recuperado de https://www.statista.com/statistics/528779/virtual-reality-market-size-worldwide/
} 
Figura 1. Crescimento e projeção do mercado mundial de realidade virtual

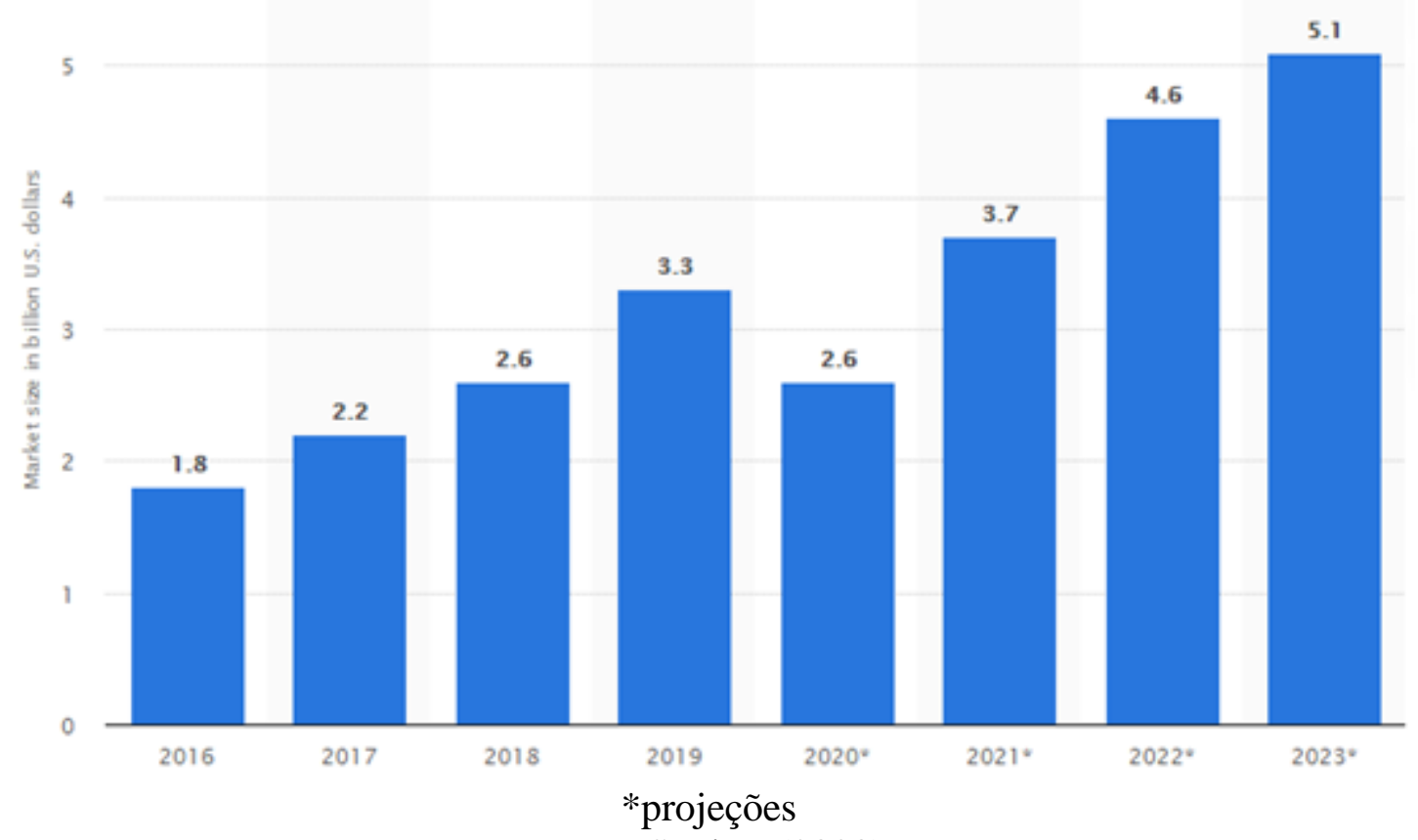

Fonte: Statista (2020)

Enquanto isso, a tecnologia inspira ações de Marketing inusitadas, como o lançamento de uma embalagem do McDonald's que pode ser transformada em visores de realidade virtual. Associado a um smartphone, o apetrecho permite acessar um jogo de esqui. Além do uso em jogos, a realidade virtual é cada vez mais presente no mundo dos negócios, tendo aplicabilidade no setor imobiliário, medicina, eventos, arquitetura e urbanismo, entre outros, atraindo gigantes como a Google, Facebook, AT\&T, Apple, Samsung e IBM ${ }^{3}$. Eventos na área de tecnologia, constantemente, apresentam novas alternativas para o uso da realidade virtual. Empresas brasileiras do segmento estão se voltando ao mercado internacional em crescimento, inclusive com incentivos da APEX Brasil $^{4}$

\section{A empresa: Rilix, a real life experience}

A Rilix é uma startup formada por dois jovens empreendedores, que incentiva outros profissionais interessados a atingir seu maior potencial a partir do seu modelo de negócios, baseados no produto inovador que comercializam ${ }^{5}$. Trata-se de uma empresa especializada em desenvolvimento e produção de hardware e software voltados ao entretenimento com realidade virtual, situada em Balneário Camboriú (SC). Iniciou suas atividades em 2014, quando, com apenas um protótipo, vendeu 13 unidades em uma feira em São Paulo. Em 2015, vendeu 100 unidades e iniciou a perceber o interesse de clientes nos países vizinhos. Em 2016, começou a vender para os Estados Unidos, Kuwait e Cingapura. Como o equipamento necessitava de um atendente, os clientes

\footnotetext{
${ }^{3}$ Época. (2016, março). Realidade virtual muito além dos Jogos. Revista Época Negócios. Recuperado de http://epocanegocios.globo.com/Caminhos-para-o-futuro/Desenvolvimento/noticia/2016/03/realidade-virtual-muitoalem-dos-jogos.html

${ }^{4}$ APEX Brasil. (2019). APEX Brasil. Recuperado de www.apexbrasil.gov.br.

${ }^{5}$ Rilix Business. (2020). Rilix Coaster. Recuperado de http://rilix.business/pt/index.html
} 
estrangeiros sinalizaram a necessidade de desenvolver um produto em que o usuário comprasse a experiência de realidade virtual diretamente em um carrinho de montanha-russa, reduzindo sensivelmente o custo. Em 2018, 30 pessoas colaboravam na Rilix. Em apenas cinco anos de existência, comercializava para 25 países, contabilizando nove milhões de usuários no mundo. A linha do tempo está sumarizada na Figura 2.

Figura 2. Linha do tempo da Rilix.

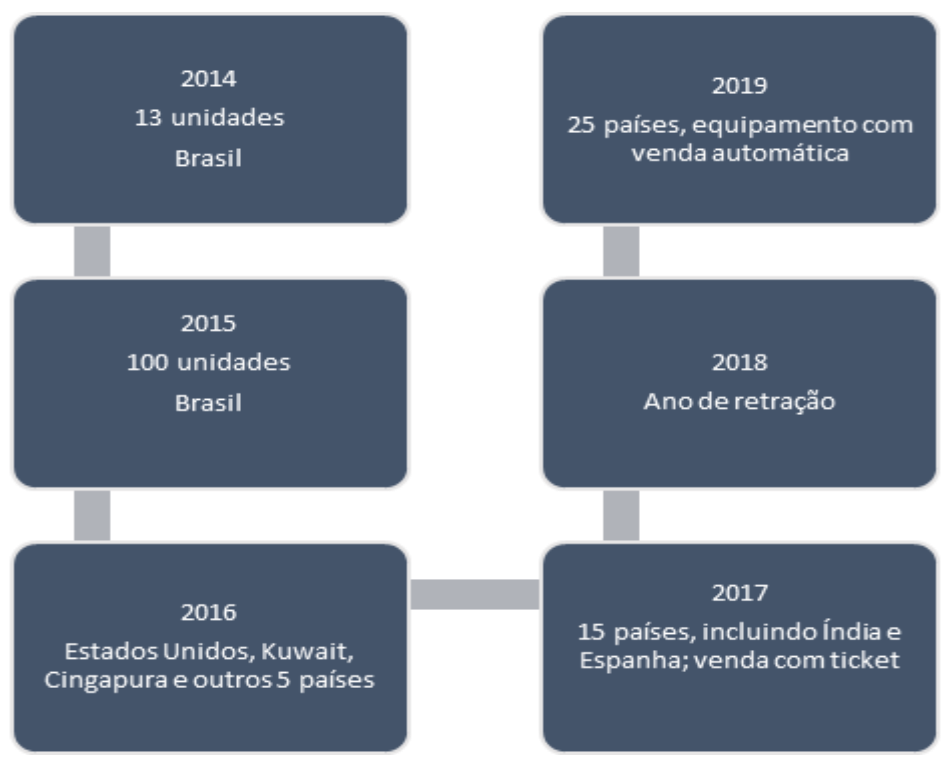

\section{Realidade virtual na Rilix}

A Rilix explora o segmento de realidade virtual voltado à diversão. A realidade virtual simula um cenário em três dimensões no qual o usuário passa a interagir com elementos, explorando o ambiente virtual ou manipulando objetos e ferramentas por meio de determinados recursos, conforme ilustrado na Figura 3.

O principal produto da Rilix é um simulador de montanha-russa que, em poucos segundos, consegue confundir a mente e os sentidos do usuário, proporcionando uma imersão completa, destacada na Figura 4. 
DILEMAS ENTRE O REAL E O VIRTUAL NA INTERNACIONALIZAÇÃO: O CASO RILIX Ananda Ferreira Martins, Sílvio Luís de Vasconcellos, Cyntia Vilasboas Calixto

Figura 3. Cenários tridimensionais de realidade virtual Rilix.
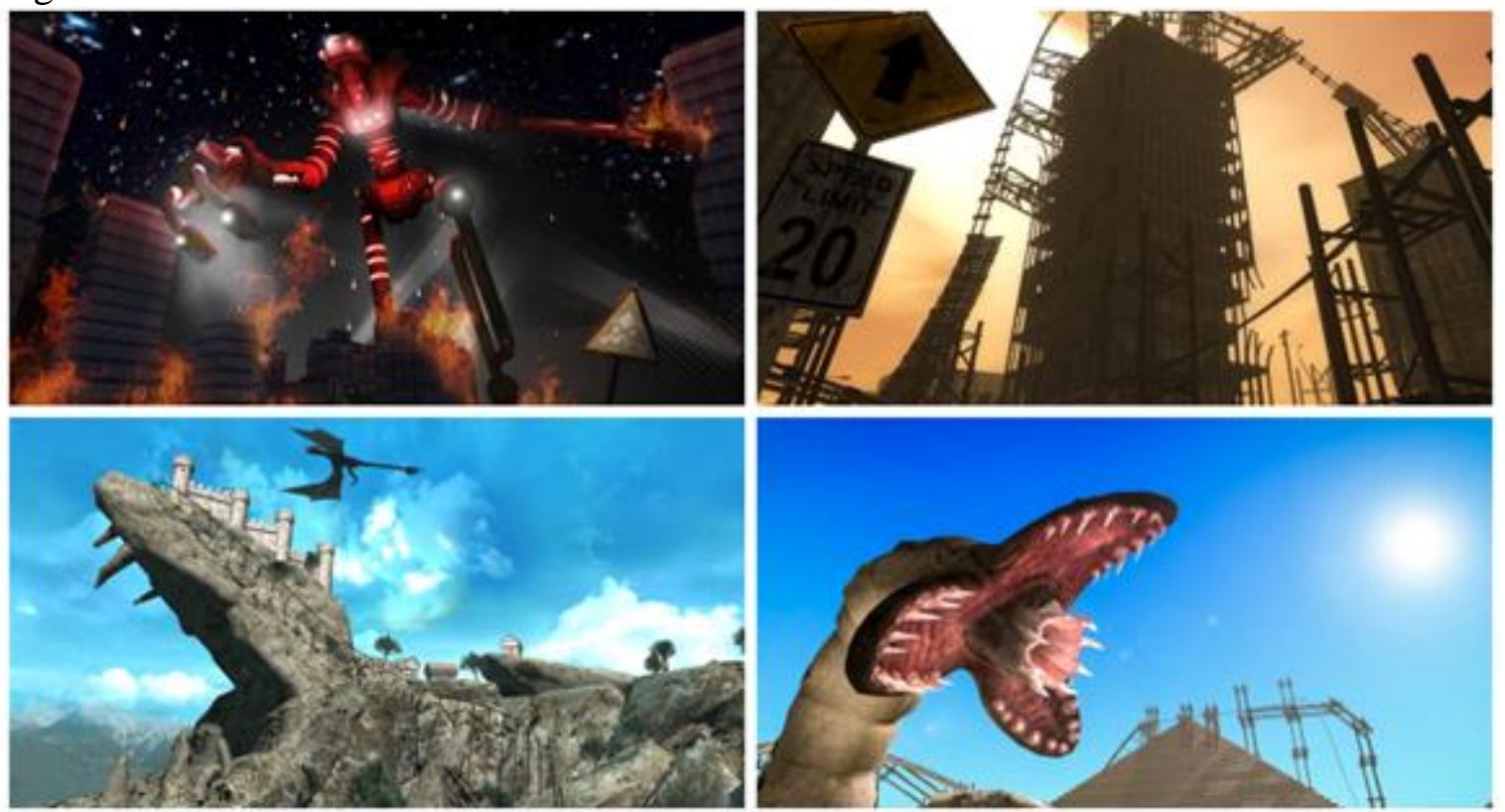

Fonte: http://rilix.business/pt/index.html

Figura 4. Modelo Rilix Coaster

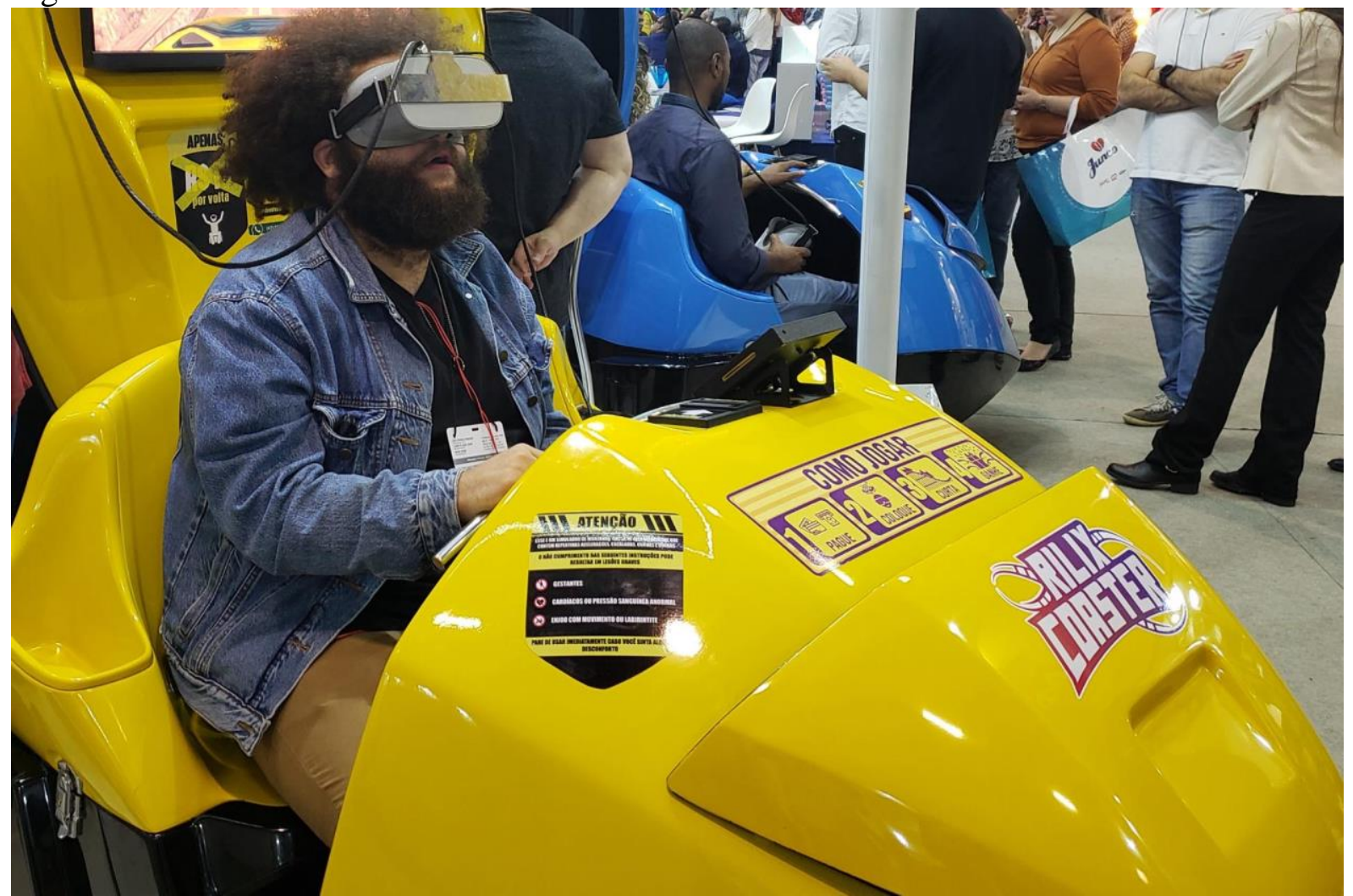

Fonte: http://rilix.business/pt/index.html 
Para usufruir da experiência que o simulador oferece, a pessoa entra em uma réplica de carrinho de montanha-russa produzido pela empresa e equipado com um sistema de vibração e de vento que aumentam ainda mais as sensações de aceleração e a imersão. O simulador contava, em 2018, com 22 cenários, desde a Ilha dos Tubarões até o Deserto Árido, e podia simular até $140 \mathrm{~km} / \mathrm{h}$. Para ter essa experiência de imersão, o usuário utiliza um visor de realidade virtual $\left(360^{\circ}\right)$ que trabalha integrado ao software do simulador. Dessa maneira, a pessoa sente-se transportada para o cenário, podendo olhar para todos os lados e enxergar os detalhes do ambiente virtual.

\section{O sucesso compartilhado}

Desde 2014, ano de fundação, a empresa funcionava nos moldes de uma organização hierarquicamente horizontal, não sendo implementado o conceito de comando e controle hierárquico ou a ideia de chefe versus empregados, que predomina em organizações voltadas à produção padronizada. O time, como se autodenominam, trabalhava em um ambiente descontraído, em que a naturalidade e a espontaneidade eram valorizadas. Conforme as demandas surgiam, o time respondia de maneira engajada e comprometida com o sentimento de propósito comum de sucesso desenvolvido entre a empresa e seus colaboradores, evidenciando o sentido da palavra sucesso, abrangendo aspectos subjetivos e intrínsecos da psique humana. Não havia ordens; os sujeitos trabalhavam com autonomia, valendo-se de criatividade e envolvimento. As estratégias alteravam-se constantemente e, por vezes, muita energia e tempo eram dedicados a encontrar a melhor opção, na intenção de pensar e repensar, questionar para decidir o que seria mais coerente para os objetivos da empresa e para as pessoas da empresa, como um todo. Era o ambiente típico de empresas da economia criativa, em que a criatividade é constantemente incentivada.

Em pouco mais de cinco meses de criação, o Rilix Coaster - seu primeiro produto - havia sido vendido para diversos estados do Brasil. Até 2018, o produto já havia sido testado por mais de sete milhões de usuários, em 15 países diferentes. Esses usuários eram atingidos com o apoio de empreendedores, que viabilizam a presença dos equipamentos em parques temáticos, shopping centers e empresas de eventos infantis. Inicialmente, a empresa vendia seus equipamentos com preço médio de R $\$ 50$ mil. Com o passar do tempo, incluiu um novo modelo de negócio em que cobra $\mathrm{R} \$ 15$ mil do cliente e vende tickets de $\mathrm{R} \$ 1,50$ por uso do equipamento (ticket), o que permite ao cliente minimizar o investimento e manter softwares de realidade virtual atualizados ao compartilhar sua receita com a Rilix, enquanto se estabelece um fluxo promissor de receita para a empresa.

A visão dos proprietários era compartilhada com seus colaboradores. Havia um entendimento entre gestores e colaboradores de que o propósito da Rilix era viabilizar a felicidade das pessoas de maneira sustentável. Defendiam a ideia de que o fim da organização não era, propriamente, o ganho financeiro; o ganho financeiro era um meio para continuar as conquistas, um desafio que priorizava a alegria das pessoas que faziam parte da Rilix.

\section{Selena e o ambiente (des)organizacional}

Aos poucos, Selena foi se ambientando com aquela (des)organização corporativa, conhecendo as pessoas que pensavam a empresa, projetavam e executavam tarefas em prol de um objetivo que foi ficando cada vez mais claro e encantador aos seus olhos: eles queriam conquistar o mundo, e ela fazia parte disso. Ela fora contratada para auxiliar nas demandas de Marketing que não paravam de crescer, mas aos poucos foi se tornando uma profissional multitarefas. Como a maioria dos profissionais recém-formados, ela queria aprender um pouco de tudo que envolvia aquele equipamento, que fazia tanto sucesso nas vendas, apesar do preço elevado. Ela queria entender do que se tratava, como funcionava, como se montava, quais as dificuldades dos clientes.

Antes de experimentar o equipamento, Selena não entendia claramente como aquele brinquedo estático provocava tantos gritos e reações nas pessoas. No entanto, quando colocou o 
visor de realidade virtual em seus olhos, em poucos segundos, tudo fez sentido. Ela podia sentir o seu corpo se mexendo na estrutura de fibra e não controlava seus gritos. Uma mistura de adrenalina e risos que ela não conseguia conter. Para todos os lados que olhava, havia um cenário, um chão, um céu, um penhasco. Era tudo proporcional, em tamanho real. Quando o carrinho acelerava, o simulador vibrava, e ela podia sentir a aceleração e o frio na barriga. Saiu do brinquedo com um sorriso de orelha a orelha, quando o diretor da empresa disse: "É isto! É isto que eu quero espalhar! Quero dar a oportunidade para as pessoas prosperarem e se divertirem. Eu quero que a Rilix vire um filme, um documentário curioso, um caso ousado de sucesso que seja discutido em sala de aula!".

Da adrenalina dos dirigentes à realidade organizacional, levou mais tempo para ela entender. Só passou a compreender o que eles diziam com "nós mudamos de ideia" e "não tem problema" quando se viu tendo que formular, reformular, se questionar e responder a demandas quanto ao modelo de negócios, o qual lhe parecia estrategicamente coerente e finalizado para ser lançado no mercado externo. Era necessária uma tradução dos sentimentos dos gestores à linguagem dos negócios. A adrenalina despertada no equipamento, de certa maneira, transbordava para a organização, e isso trazia desafios que ela não havia aprendido em anos de faculdade ou na pósgraduação.

Por outro lado, os compradores do exterior queriam adrenalina nos seus clientes, mas viviam a realidade do modelo racional de tomada de decisão. A máxima "mudar de ideia" passou a ser uma rotina. Se percebiam que estavam indo pelo caminho errado, ou se, de alguma maneira, as decisões que estavam tomando não faziam sentido, paravam tudo e reformulavam o plano. Era difícil harmonizar o cliente racional e a cultura prevalente na empresa, pois ideias, prazos e orçamentos tinham sentidos diferentes para quem produzia e para quem comprava.

Mesmo dentro da empresa, a forma espontânea de gestão incomodava algumas pessoas do time. A falta de gerenciamento, prazos ousados, descontrole de gastos ou investimentos, programação, entre outros fatores, começaram a gerar desconfortos. Algumas pessoas clamavam por organização, prazos, hierarquia. Uma reestruturação fazia-se necessária. No seu terceiro ano de existência, em 2017, a empresa estava diante de um impasse que, potencialmente, mudaria a filosofia desenvolvida até ali e que se refletiria em sua cultura organizacional: optar por mudar para uma estrutura de gestão mais formal - que facilitasse o cumprimento de prazos, a padronização e economias de escala, alinhada com os negócios internacionais - ou manter-se em sua estrutura orgânica, mais flexível, com menos níveis hierárquicos, que transformou a empresa em sucesso, com destaque para sua capacidade de inovar e criar novos produtos e cenários virtuais? Seria possível conciliar esses modelos?

\section{A reestruturação da Rilix}

Diante do desafio, foram estabelecidas metas mais específicas, nomeados gestores responsáveis e executores de tarefas por setores. Surgiram os prazos mais bem-definidos, funções determinadas e delimitações. Parte do time aderiu a o que se nomeou Time Brasil, adotando uma gestão que seguia o padrão conhecido e difundido no universo empresarial, com hierarquia verticalizada, funções e cargos definidos, cumprimento de horário para os colaboradores, reuniões de avaliação, indicadores e alinhamento periódicos. Essa área se responsabilizaria pelos aspectos formais da Rilix, desde a área financeira, recursos humanos, comercial nacional e América Latina, além da produção. A outra parte do time seguiria as diretrizes do modelo de negócios original, que foi denominado pelo grupo como Time Mundo, com um mínimo de hierarquia, encarregado de inovar e expandir os negócios para fora do continente, com orientação de gestão mais orgânica.

Embora os dois grupos se distanciassem diametralmente, guardavam alguns pontos em comum. Por exemplo, a transformação de colaboradores em sócios, a ânsia de atingir resultados excelentes, a conquista de novos mercados preconizada pelos proprietários, fluidez de ideias e 
produtividade. Porém, os modelos de gestão diferentes começavam a gerar conflitos de difícil conciliação. Se, de um lado, era necessário registrar horas trabalhadas, no outro, a métrica era medir satisfação e engajamento da equipe pelas horas dedicadas sem remuneração extra. $O$ Time Mundo propunha ousadia e ativação do gatilho da psique humana capaz de movimentar montanhas: o pertencimento, como instrumento de coesão entre líder e liderado, na busca de consolidar equipes de excelência, resultados extraordinários e hierarquia horizontalizada. Era incentivada a percepção de que todos eram sócios de seus sonhos. Por isso, trabalhavam sem ganhar horas extras.

O Time Mundo era responsável pela pesquisa e desenvolvimento de novos mercados, internacionalização para mercados distantes, suporte técnico internacional, estratégias de Marketing e de comunicação e posicionamento de marca. Dadas as incompatibilidades, a alternativa foi separar fisicamente a empresa em duas partes, estabelecendo-se unidades em endereços distintos. $\mathrm{O}$ mercado-alvo do Time Brasil foi definido como Brasil e América Latina, enquanto o resto do mundo ficou sob o encargo do Time Mundo, embora o objetivo da internacionalização continuasse sendo algo em comum.

\section{O desafio da internacionalização}

Dentro da Rilix, Selena estava organizando sua mudança para o novo prédio, quando o outro sócio, Franco, lhe chamou para conversar. Ele falou sobre o desafio de internacionalizar a empresa e a questionou sobre a possibilidade de ficar em seu grupo, Time Mundo, por mais um período e ajudar a planejar esse passo, dado que a área de Marketing havia ficado com esse time. Sua formação em Relações Internacionais indicava que aquele convite algum dia viria. O que ela desconhecia era o quanto aprenderia sobre liderança, capacidades, modelos de negócios, motivação, metas, prazos e planejamento durante o processo de internacionalização, ao vivenciar o conflito entre os modos de gestão dominantes no Time Mundo e o universo da competição em mercados internacionais.

Os primeiros dias no Time Mundo foram um pouco estranhos para Selena. Primeiramente, porque era composto por um número bem reduzido de pessoas. Além disso, o objetivo parecia, de uma forma geral, um tanto vago, considerando a realidade da maioria das pessoas sem preparo, embora dedicadas, que compunham a equipe. Tinham um sonho, mas não conseguiam vê-lo se materializando. Foi quando surgiu um convite para uma feira de tecnologia em Amsterdã, na Holanda. $\mathrm{O}$ organizador entrou em contato com a empresa, oferecendo um espaço gratuito para que pudesse expor seu produto em uma zona da feira destinada somente a produtos tecnológicos e lançamentos de novas experiências. O prazo era curto, porém ela descobriu que seu time era apaixonado por prazos ousados.

Aceitaram a proposta e iniciaram a corrida contra o tempo para produção e finalização da nova estrutura do simulador. Precisavam adaptar um projeto neozelandês, com um design inovador que remetia a um carrinho de montanha-russa de verdade, produzido de maneira toda desmontável, o que reduziria os custos logísticos. Iniciaram os testes com o sistema de ventilação e vibração, aperfeiçoaram os cenários e experiências, prepararam os documentos e orçamentos para o estande da feira, compraram as passagens, locaram uma casa e dedicaram-se integralmente para viabilizar sua participação no evento. O propósito era claro, o prazo, curto, e urgência era a palavra-chave. Cada membro da equipe trabalhava de maneira autônoma, porém nitidamente engajado com o objetivo e o prazo.

\section{A feira e o choque}

A participação da Rilix na feira seria em um espaço destinado a novas tecnologias e startups. A feira era gigante, com 15 pavilhões preparados para recepcionar mais de 55 mil pessoas em busca de novidades em mídia eletrônica e entretenimento. Trabalhavam durante horas a fio durante o evento. A experiência que proporcionavam aos visitantes era uma atração à parte na área da feira 
denominada Zona do Futuro. Havia fila para experimentar o simulador e muitos investidores interessados em fazer contato e receber propostas comerciais. A feira era um mar de oportunidades para as empresas que soubessem aproveitá-las. À medida que os preparativos do estande se iniciaram e a feira começou, no entanto, iniciou-se um processo de estranhamento no comportamento do time.

O time estava confuso, disperso e desmotivado. Anteriormente, essa falta de ânimo já havia acontecido, mas de maneira pontual. Um colega ou outro não estava em uma boa semana, ou estava com alguma dificuldade em casa. Podiam, nesses casos, contar com os diretores para conversar e lembrar como o propósito da Rilix era nobre e possível de acontecer com dedicação total. Porém, durante a feira, até os líderes pareciam estar desmotivados. Realizavam reuniões extensas, após os longos dias de trabalho tentando alterar a estratégia, a proposta de negócio, as atividades diárias. Buscavam solucionar questões pessoais que pudessem estar afetando o desempenho do grupo, porém nada adiantava. O comportamento dos diretores influenciava a reação de cada membro do time, e, gradualmente, cada integrante do grupo ia perdendo o entusiasmo em relação à oportunidade que estavam vivendo. A perda de identidade, os objetivos difusos e a fragilidade da liderança, naquele espaço e tempo, revelaram uma equipe desmotivada e pouco produtiva. $\mathrm{O}$ equipamento estava pronto para a internacionalização, mas a equipe, aparentemente, não.

Pouco a pouco, uma névoa de incertezas se instaurava em cada integrante da equipe, que se questionava se teria sido muito audacioso lançar-se naquela missão internacional. Se, por um lado, a oportunidade de iniciar a empreitada e conquista do mercado europeu surgia, por outro, os níveis de exigência e perfeccionismo dos investidores e clientes iam muito além de problemas comportamentais dentro da Rilix. Logo perceberam que não haveria segunda chance para causar uma primeira boa impressão aos olhos do tão exigente público internacional, e, por isso, precisavam reagir.

Precisavam reduzir ao máximo riscos e falhas, no que diz respeito tanto ao funcionamento do produto quanto da equipe como um todo. Entretanto, era apenas a ponta do iceberg no que diz respeito aos desafios a serem transpostos pelos líderes da empresa. Os laços que mantinham cada membro da equipe engajado parecia estar se dissolvendo, justamente em solo europeu. Por ironia ou destino, os líderes, que antes mantinham a chama acesa, agora tinham um olhar sem esperanças em relação a seus métodos de gestão quando olhavam para seu time. $\mathrm{O}$ mais precioso dos bens, como sempre preconizavam, agora era um grupo desmotivado e descrente.

É provável que, em um modelo de gestão mais verticalizado, esse cenário pudesse ter sido evitado, com exigências mais bem-definidas e um planejamento delimitado em etapas. Entretanto, esse não era o perfil do Time Mundo, que lá estava, sem liderança definida, sem referências, sem um padrão que servisse de suporte para tomar decisões diante de tantas oportunidades, tantos investidores, tantos olhares estrangeiros maravilhados com a experiência que o Rilix Coaster proporcionara.

De seu ponto de vista, Selena só conseguia observar que a possibilidade de impulsionar a internacionalização da empresa a níveis jamais vistos estava escapando por entre os dedos. Ela, por vezes, pensava em sacudir cada membro da equipe até que todos despertassem do transe para a oportunidade que estavam perdendo de impressionar estrangeiros globais, de transformar o seu destino por meio do Rilix Coaster. Assim como numa montanha-russa, a equipe, que já tinha atingido o êxtase com a possibilidade da participação na feira, agora estava com falta de ar e cambaleante. $\mathrm{O}$ caos de suas próprias expectativas parecia um looping infinito, mas a experiência ainda não tinha terminado. Será que a equipe vai pedir para parar o brinquedo à organização do evento ou ainda dá tempo de recuperar o fôlego e prosseguir com o coração pulsante? 


\section{Questões para discussão}

1. Até o início do processo de internacionalização, a Rilix se autodenominava uma empresa orgânica, em que os propósitos da empresa e de seus colaboradores eram compartilhados. Em seu ponto de vista, existe alguma limitação em termos de setor, produtos, serviços, ou mesmo porte, que permitam que uma empresa mantenha uma estrutura orgânica, hierarquicamente horizontal, em contraponto aos modelos mais tradicionais de gestão?

2. Em determinado ponto, os gestores ofereciam aos colaboradores um sonho compartilhado de autorrealização, em que os resultados da empresa não eram o fim, e sim o meio da realização de todos. Você concorda com essa premissa? Até que ponto isso é sustentável? Há grandes empresas que mantêm esse formato?

3. Considerando que a empresa possuía uma estrutura orgânica, portanto sem funções determinadas e com flexibilidade em termos hierárquicos, como poderia manter controle sobre o que foi planejado e o que foi atingido? É possível definir indicadores nesse tipo de estrutura? Como se manter lucrativa e tornar-se uma empresa inserida em diferentes mercados no exterior sem que haja uma estrutura formal, com papéis definidos em sua gestão? Seria a hora de experimentar outros modelos de negócios? O que você recomendaria?

4. No caso apresentado, a empresa buscava a internacionalização, porém, aparentemente, estava insegura sobre o próximo passo. Se for considerado que a internacionalização pode ocorrer por exportação, licenças, joint-venture e investimento direto no exterior, que forma seria mais recomendada para a Rilix expandir-se internacionalmente? E Selena, era essa a chance de ascender profissionalmente que tanto esperava? 